\title{
AUTOMOBILE ACCIDENTS, TORT LAW, EXTERNALITIES, AND INSURANCE: AN ECONOMIST'S CRITIQUE
}

\author{
WILLIAM VICKREY*
}

It will be no news to the readers of this symposium that the cost of traffic accidents in the United States, even on a crass material level, is staggering. Yet it may help to put the matter in perspective to note that this cost, estimates of which range from a minimum of $\$ 8$ billion to over $\$ 12$ billion a year, is of roughly the same magnitude as the entire annual cost of providing the roadways on which these accidents occur. ${ }^{1}$ While much effort has been devoted to ascertaining how the cost of the highway should be apportioned among various classes of traffic, little attention has been given by economists to the question of how the cost of accidents should be borne, even in the face of the open scandal that less than half of the amounts paid as premiums and uninsured judgments ever reaches the injured, the remainder being frittered away in commissions, administrative expense, and legal fees.

\section{I}

\section{LAW Versus ECONOMICS}

\section{A. Fault Versus Externality}

To the jurist, the question poses itself as one of under what circumstances, and to what extent, losses suffered in the first instance by one party should be shifted to another and possibly eventually passed on to a class of loss-bearers. In this process it is axiomatic that, aside from criminal penalities, amounts payable by those to whom liability attaches, less whatever costs of transfer or adjudication are involved in the process, should equal the amounts receivable as compensation. In traditional tort law, the main occasion for such shifting is the fault or culpable negligence of one of the parties, looked at ex post, with the aid of such doctrines as that of "contributory negligence" and "last clear chance."

Even if the jurist goes so far as to admit that liability should attach to some degree and in some cases even when no error or misconduct can be imputed to the responsible party, the liability is to be measured by the compensation payable, and if payment of compensation is not feasible, no civil liability will attach. Thus

* B.A. I935, Yale University; M.A. 1937, Ph.D. 1947, Columbia University. Professor of Economics, Columbia University. Center for Advanced Study in the Behaviorai Sciences, 1967-68.

${ }^{1}$ See, e.g., Nationai Safety Councin, Accident Facts (I968 ed.); The Economist, July 13, 1968, p. $x x i$.

' See generally W. Prosser, Handboox on the Law of Torts 426-43 (3d ed. 1964); 2 F. Harpir \& F. James, The LaW of Torts Ir93-1263 (1956); C. Morris, Morrus on Torts 21 I-26 (1953). 
if an unattached person is killed, there may be little or no liability, whether the individual is a Bowery bum or an Einstein. Or if a car breaks down in a narrow spot in the road during a period of heavy traffic, the aggregate delay to other motorists may be evaluated in many hundreds of dollars, but again, since payment of a dollar or so to each is impractical, no liability ensues. In this case the maxim de minimis non curat lex applies to each individual share, not to the amount of the damage to the community as a whole.

Moreover jurisprudence tends in principle, though less in practice, to draw a sharp line between licit and culpable behavior. Action that fails to transgress this line may be held to involve damnum absque injuria and carry no penalty, however great be the damage done to others and however small the potential benefit to the actor. The economist tends rather to take natura non facit saltum as his motto, and to insist that the degree of culpability and accountability is measured by the damage done and not by any arbitrary line defining the limits of acceptable behavior.

\section{B. The Separability of Cost Assessment and Compensation}

Further, for the economist there are two distinct questions: (I) the decision as to what charges should be assessed against an actor for conduct involving actual injury to others or an increase in risk of injury to others, and (2) a separable decision as to what compensation should be paid to those injured and under what circumstances. It may be convenient but it is not logically necessary that the aggregate of charges assessed should just cover the payments to the injured, including the overhead costs involved. If there is a discrepancy, to be sure, there is a supplementary question of what should be done with the excess funds in the one case or from what source the deficit should be made up in the other. Even though as a matter of convenience it may turn out to be desirable to adjust matters so that there is neither surplus nor deficit, in principle it is a help to clear thinking if the two matters are kept separate. It turns out in fact, as we next demonstrate, that the theoretically appropriate level of charges to actors would far exceed, in the aggregate, the total cost of making compensation payments to individual victims at an appropriate level (including the very substantial overhead of commissions, fees, underwriting profits and court costs of the entire process), though in some instances the excess can be thought of in terms of a rental for the roadway facilities used.

\section{Specific and General Levels of Assessment of Costs and Choices}

To an economist, a major factor in determining assessments on hazard-creating actors is the desire to influence their actions in the direction of a more efficient allocation of resources. This assessment can take place on two levels: assessment as a consequence of particular accidents or assessment on the basis of the hazardous activity independent of the involvement of the individual in actual accidents. The basic consideration here is that an actor has a choice among alternative actions 
and modes of action, that his choice can be an efficient one only if it is made in terms of a proper weighing of all the consequences likely to follow from the various alternatives, and that normally it is only if these consequences are fully brought home to him as a cost, directly or indirectly, that he will be motivated to make the decision that will properly balance advantages and disadvantages to himself and others.

A corresponding distinction can be made, at this point, between choices concerning what gross activity one is going to engage in-for example, riding a bus, driving a car via route $\mathrm{A}$, or driving via route $\mathrm{B}$-and the choices concerning the manner in which one carries out the activity-for example, whether one is going to drive carefully or absent-mindedly or even recklessly. In the former case, the choice is an observable one and charges can to a considerable extent be adjusted according to the choice made, while in the latter case the choices are to a large extent unobservable and their consequences for risk of accident are not easy to gauge. In the former type of case it is possible at least in principle to bring appropriate influence to bear by $e x$ ante charges relating to the gross activity, whereas in the latter case the only way in which the appropriate degree of influence can be brought to bear on the behavior of the individual is through an ex post assessment related to damage actually inflicted on others.

Indeed, if it were not for the catastrophic nature of accident losses in relation to the resources of the individuals involved, economic efficiency would be best served by exacting from every individual who takes action as a result of which damage is inflicted on others that would have not have occurred in the absence of this action a payment equal to the full amount of the damage so inflicted. Moreover, what will sound strange to the juristic mind, the assessment should be independent of any criterion of fault or relative contributory negligence and furthermore should not be abated or offset in any way by compensation for injuries suffered by the actor himself!

This result is a direct consequence of the fact that in most of the accidents with which we are concerned there are two or more parties involved, and the damage involved in the accident could have been totally avoided if any party had acted differently, whether by driving less recklessly in the case of the "guilty" party, or by driving more defensively in the case of the "innocent" party, or by accomplishing the purpose in some way not involving the specific activity at all, as by travelling by train rather than automobile, or by living closer to one's place of work, or even by giving up the object of the trip entirely. The full damages caused by the accident are part of the "marginal social costs" of each of the activities contributing to the accident. Double (or triple or more) counting at this point is correct; none of the activities involved in the accident were economically justifiable unless they were able to bear the full costs of accidents which would be avoided if the activity were not undertaken, including whatever overhead costs are necessary, under prevailing institutional arrangements, to provide appropriate payments to victims. 
Economically speaking, it is just as important to provide an adequate incentive for driving defensively rather than merely nonnegligently as it is to provide an incentive for driving nonnegligently rather than recklessly. Systems which require payments by the actors only in case of fault and only to the extent of the compensation received by others (even with expenses of adjudication and administration added) fail to give an adequate incentive for seeking out alternatives not involving the increased risk of vehicular accident.

\section{Marginal Versus Average Accident Costs}

This notion that proper imputation of marginal costs for purposes of economic efficiency requires, in the case of the pure two-car accident, that each party be charged the full cost of the accident, and that the accident be "paid for" twice over, may at first seem bizarre, but is nonetheless correct, at least on the assumption that the absence of either vehicle from the scene would not only have averted the accident that happened but would not have given rise to some alternative accident. This assumption is, of course, not entirely accurate. In some cases one of the cars involved constitutes, either from a mechanical defect or the habits of the driver, an "accident looking for a place to happen," and had the second car not been present at the critical place and time some other accident would have happened at a subsequent time. To some extent, also, the presence of high volumes of traffic induces a greater degree of caution or discipline on the part of the drivers, so that in spite of the fact that any given car has a larger number of encounters in going from one place to another under heavier traffic conditions, accidents do not increase in proportion to the number of such encounters. And of course if traffic is so heavy that speed is reduced to a crawl, fatal accidents become almost impossible. There are also the "single-car accidents," in which the presence of other cars is not a factor, though many accidents reported as single-car accidents actually occur as a result of evasive action caused by the presence of the car that got away scot-free.

Nevertheless, on balance the statistical data do seem to show that accident rates increase significantly with increasing traffic flows over the more significant ranges. Accident data for California freeways for the year 1960 through $1962^{3}$ show that on thirty-two four-lane freeway segments with average daily traffic of between 21,500 and $3 \mathrm{r}, 600$, the accident rate averaged $\mathrm{I.I} 8$ per million vehicle miles, while on twenty segments with average daily traffic between 31,600 and 46,500 , the accident rate averaged $\mathrm{r} .45$. In the former class an average of $6,35^{\circ}$ vehicles per lane per day produced 7.493 accidents per 1000 lane miles per day; in the second an average of 9,600 vehicles per lane per day produced 13.920 accidents per rooo lane miles per day. According to these figures an increase in traffic flow of $325^{\circ}$ vehicles per lane per day would generate an increase in the accident rate of 6,427 accidents per 1000

\footnotetext{
${ }^{3}$ R. Lundx, The Effect of Traffic Volumes and Number of Lanes on Freeway Accident Rates (Cil. Div. of Highways, Traffic Bull. No. Ix, July 1964).
} 
lane miles per day, or an incremental accident rate of r.98 accidents per million vehicle miles, as contrasted with the average rates of 1.18 and 1.45 respectively for the two classes of road segments. For four-lane freeways as a whole, the marginal accident rate is $\mathrm{r} .46$ times the average accident rate; for six-lane freeways the ratio is $\mathrm{I} .5 \mathrm{I}$, and for eight-lane freeways $1.60{ }^{4}$

Unfortunately no comparable figures are at hand for urban streets or even highways in general, due largely to the difficulty of classifying miscellaneous highways according to physical characteristics. There is, however, the indication furnished by insurance rates, which are up to four times higher for comparable coverage in congested areas than in uncongested areas.

If, then, there is such an excess of marginal accident costs over average accident cost-which would imply that users of public highways should pay for their use something more, on this account, than is necessary to make good the actual losseswhat happens to the excess? In the short run, this excess can be considered part of the scarcity rent payable for the use of the facilities. In effect, this excess represents the extent to which the spreading of the traffic over more routes or more lanes would have diminished the cost of accidents, and in a world of constant returns to scale, the adding of this rent to other rents due to congestion delays and the like would produce a sum just sufficient to finance the optimum extent of highway construction. In practice it is likely that significant economies of scale exist in the construction of rural highways at least and that therefore the optimum level of rural highway development is somewhat greater than that which could be fully financed on this basis. On the other hand, urban highway and street facilities are more likely to be expansible only under conditions of increasing costs, and in this case optimum development would stop well short of using up all of the rents in financing the facilities.

\section{Accident Rates and Rents}

There is, thus, a rather serious logical problem of keeping disentangled the amounts paid by reason of accident causation and amounts paid as rentals for use of the facility on which the accidents occur. One could, indeed, think of payment for use of the facility in two parts: a payment with respect to average accident incidence, and a payment for the privilege of travelling on less congested or more ample roadways where the incidence of accidents is less than it would be on a more congested

\footnotetext{
"Too much importance should not be given to these precise figures, as they relate to the number of accidents and not their cost. While one would normally expect that the heavier traffic routes would generate accidents of greater severity-in particular more cars involved per accident, on the averagethere is on the other hand some indication that the number of fatal accidents does not follow this pattern. There is also some indication that for very low-traffic segments the rclationship is reversed; this tendency may reflect largely the fact that many of these segments are newly opened ones with a rapid build-up of traffic over the year, with many more drivers being unfamiliar with the alignment, temporary end-of-fieeway conditions, etc., or possibly without the beneficial effect of a certain minimum amount of traffic in making it less likely for cars to get into the wrong roadway, or in indicating curves at night. Such segments accounted for only $3 \%$ of the total traffic, however.
} 
or narrower road. One cannot, then, consider the problem of how much the motorist should pay with respect to the impact of his use on the accident rate without at the same time considering how much he pays for the use of the road in relation to other cost factors, i.e., in relation to (I) the cost of enlarging the roadway network in the long run, or (2) the congestion costs (delay, additional fuel costs, etc.) in the short run. And while congestion and accident rates are correlated to a considerable extent, nevertheless the variation in congestion costs between lightly travelled roads and heavily travelled roads is far greater than the variation in accident costs, so that for the lightly travelled rural road it is the accident cost that is the dominant factor, while in the urban and suburban areas, especially at peak traffic periods, it is the congestion cost rather than the accident cost that is the dominant factor.

\section{II}

\section{ExternaLITIES AND INSURANCE}

A. Subsidization of Motor Vehicle Use Through Externalizing Accident Costs

But even if one would be willing to assume that the excess of marginal accident cost over average accident cost is taken care of by motor vehicle taxes viewed as rentals of roadway space, under present conditions not even the average cost is borne by the motor vehicle economy. The Michigan study of accident compensation for accidents occurring in the year $195^{5}$ showed that of total losses amounting to $\$ 178.2$ million, suffered by I0I,500 individuals involved in 59,100 bodily injury accidents, with 86,I0o injured and I7x9 deaths, compensation had been obtained in the amount of only $\$ 85.2$ million from all sources during the period of about three years between the time of the accident and that of the study interviews; in addition, there were expectations of eventually obtaining another $\$ 8.4$ million for a total of $\$ 93.6$ million, leaving $\$ 84.6$ million to be borne by the accident victim himself. In those cases where the uncompensated or incompletely compensated accident victims were pedestrians or roadside property owners, the loss was shifted outside the automobile economy, and therefore represented a form of subsidy to the automobile.

Of the $\$ 85.2$ million received in compensation, $\$ 46.7$ was received in the form of tort settlements and $\$ 17.5$ million from the victim's own automobile insurance, leaving \$2I million as amounts received from sources not related to the operation of automobiles, such as medical and hospital insurance, life insurance, sick leave payments by employers, social security, and the like. Thus a substantial part, at least twelve per cent and possibly as much as twenty to twenty-five per cent, of the costs of accidents resulting from the operation of automobiles is borne in a manner not impinging in any direct way on the operation of automobiles.

Even to the extent that this cost is borne by automobile users, it is borne through an extremely costly mechanism and in a manner not particularly conducive to

\footnotetext{
${ }^{5}$ A. Conard et al., Automobile Accident Costs and Payments i37-58 (1964).
} 
evenly balanced decisions between the use of automobiles and other alternatives. There are of course the well-documented complaints regarding the inequities and wastes involved in the current tort-liability-insurance system, epitomized in the conclusion that of the value of the premiums paid for such insurance by policyholders, less than forty-five per cent reaches the injured persons, ${ }^{6}$ and that in a highly capricious manner, with generous and even duplicative payments to some, and catastrophically inadequate payments to others. The remaining fifty-five per cent goes to commissions, expenses, profits, court costs and lawyers' fees. ${ }^{7}$ But even if the system were to work without overhead costs, there is in addition the frequently overlooked fact that the manner in which premiums are computed and paid fails miserably to bring home to the automobile user the costs he imposes in a manner that will appropriately influence his decisions.

\section{B. Inappropriate Patterns of Premium Payment}

Premiums are paid generally on a periodic basis, varying chiefly in terms of the characteristics of the usual drivers, the location where the car is normally kept, and the character of the use. The difficulty is that while these parameters may come as close as any available to the insurers to permitting rates to be set for different classes of risks, they provide incentives that are largely inappropriate at the margins where decisions are actually made as to whether to maintain a car and whether to make a given trip by car.

The basic difficulty is that the insurance premium appears to the individual automobile owner almost entirely as part of the fixed cost of owning a car. The amount of the premium, given the coverage he selects, is fixed by factors largely independent of most of the decisions that are at all marginal as to how much he will use his car. The only attempts that are made to vary premiums in relation to use are typically to classify the risk according to whether and how far the car is driven to work or whether it is used in business; the classifications are very broad and to a con-

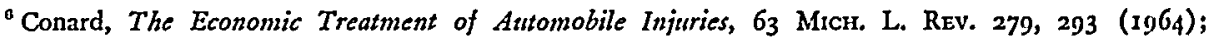
Conard, Remarks, 1967 U. Irl. L.F. 440, 451. See Franklin, Chanin \& Mark, Aecidents, Money and the Law: A Study of the Economics of Personal Injury Litigation, 6I CoLum. L. REv, I, 20-30 (I961), for a similar conclusion.

${ }^{7}$ Even though the existing insurance system results in roughly doubling the cost of the portion of the total that is covered by insurance, this cannot be taken as an offet to the failure to allow for the cxcess of the marginal over the average cost as discussed previously. Given the prevailing institutions, overhead costs are as much a part of the marginal cost of the hazard-creating activities as the direct losses to the victims themselves. These costs, too, according to this analysis, should be charged on a marginal basis, i.e., duplicatively against each party to a two-car accident.

If these overhead costs could be eliminated, the present level of charges would then represent approximately the appropriate level of generalized deterrence to enlarging the amount of hazard-creating activity, since the real costs of accidents would then have been reduced. But as long as the costly methods of dealing with the problem persist, the present level of the hazard-creating activity is excessive and the level of generalized deterrence inadequate. And as will be seen below, even if the generalized level of deterrence were correct, the detailed manner in which it impinges on the levels of activity are inappropriate to producing an optimum level of activity, wholly aside from the influence that such charges might have on the degree of care exercised in carrying out the activity.
} 
siderable extent are based on the unverified statements of the applicant. Moreover, the variations in premiums based on such classifications remain relatively small. The result is that with the possible exceptions of the decision as to whether to drive to work or use public transportation, and of the decision as to whether younger nembers of the family are to be allowed to drive at all, the added exposure to risk involved in added usage is not brought to bear on the decision.

Even to the extent that the premium might in principle be affected by the usage decided upon, the differences in premiums are minor relative to the possible differences in exposure. The fact that the differentials are based largely on the unverified representations of the policyholder makes it difficult to apply more substantial differentials, especially in the face of competition: to have differentials that would present too strong a temptation to misrepresentation would overload the company offering such differentials with risks that are not only misrepresented but involve policyholders with less integrity and responsibility, who may be correspondingly poor risks on that account. Especially when it comes to renewals, policyholders who would not directly misrepresent their position may be more negligent in informing the insurer of adverse than of favorable changes in their status.

When it comes to decisions as to whether to maintain a car, or perhaps a second or third car, the cost of insurance appears in most cases as an excessive deterrent. The individual who is on the margin of decision is more likely to be one who if he decides to maintain the car will be using it substantially less than the average or, especially in the case of the second car, will be on the margin precisely because the occasions when the two cars would be in use simultaneously will be less frequent, so that the availability of the second car would add relatively little to the total mileage. To be sure, moderate discounts are often allowed by insurers for the insurance of a second car under the same ownership, but the discounts that could be offered on this basis, even if they could be made sufficient to reflect fully the difference in exposure for the classification as a whole without stimulating fictitious nominal arrangements, would still not eliminate the overcharge of the marginal car.

Moreover, the problem of reliance on the representations of the insured is much more serious than with fire, life, and other types of insurance where it is possible to rely at least on the possibility that investigation at the time of casualty will reveal any gross misrepresentation; this possibility is much less significant in the case of automobile liability insurance. Moreover, to permit the insurer to avoid liability on the ground of such misrepresentation would to that extent make compulsory insurance and financial responsibility laws ineffective in protecting the innocent victims.

\section{Correcting the Premium Structure}

The premium structure thus has the general effect of promoting excessive use of a given stock of cars and undue stinting on the ownership of cars (a fact, incidentally, 
which should engage the attention of the automobile industry). To be sure, a premium structure that varied in strict proportion to mileage might be held to go somewhat too far in the other direction, in that cars driven more intensively may be driven more skillfully (though not necessarily as carefully), so that the risk of accident would not be proportional to the mileage. But it seems unlikely that premiums proportional to mileage would be as far from the mark as the present pattern.

There is no real conceptual difficulty in charging an insurance premium according to mileage; the problem is one of implementation. If it were not for the widespread practice of turning back odometers, it would not be too difficult for insurance companies to charge premiums subject to a rebate figured on the odometer reading at the end of the year, creditable on the next year's premium. Although stock companies in particular have been reluctant to engage in retrospective rating of single-car risks, both in terms of the transaction costs and the resistance of policyholders to making larger initial premium payments, the experience of dividend-paying mutual companies would seem to indicate that these difficulties are not insurmountable. Proposals that are afoot to make it illegal to reset odometers, primarily on grounds of honesty in trade with respect to used cars, coupled with the development of more tamperproof odometers by automotive manufacturers might in time make such a procedure practical.

A close alternative would be to tie the insurance premium to the sale of tires or gasoline. Indeed the notion of motor vehicles using "insured tires," whereby the manufacturer of the tires or an associated insurance company identified in some way on the tire itself, would be responsible for indemnifying the victims of any accidents in which the vehicle using the tires may be involved has a certain attraction. Coverage could be suitably varied in accordance with a supplementary contract in which the serial number of the tires would be referred to; for most users, however, a standard minimum coverage could be presumed in the absence of any such supplementary contracts. Another attractive feature of such a scheme would be that the high tirc wear associated with high speeds would imply higher effective premiums per mile. The association of accident liability with tire manufacture would also provide additional incentive for the manufacturer to develop tires with safety features that are actually effective (instead of merely features that can be advertised as promoting safety).

To avoid an undue tendency to use the tires beyond the point of safety, it would be necessary to provide some form of credit based on the weight of used tires turned in, which would in turn present a significant added administrative expense. Even this, however, should prove much less costly than the present commissions and other expenses in conjunction with the writing of insurance policies.

The main serious defect in the insured tire concept, however, is that it would not permit adequate geographical variation in the rates: there would be no way of preventing tires purchased in a rural low-risk area being used predominantly in 
a congested high-risk area. It would still be possible to sell insured tires at rates reflecting use predominantly in high risk areas, and leave those who drive primarily in lower risk areas to seek some other form of protection. But it does not seem that the advantages of such a scheme would be sufficient to warrant the setting up of a separate scheme to cover only a fraction of the problem, while as a universal or even predominant scheme the difficulties seem too great.

The corresponding notion of "insured gasoline" may have more to recommend it. Indeed, in those jurisdictions such as Saskatchewan ${ }^{8}$ with a compulsory state scheme of insurance, it would seem that it would be more equitable and less costly in terms of administration to collect the premiums paid into the fund in the form of a surcharge on the gasoline tax rather than as periodic premiums of the conventional sort. Such a gasoline tax surcharge would also be extremely appropriate if, as under the proposals under consideration in New Zealand, ${ }^{9}$ victims of all kinds of accidents are to be made eligible for compensation on a uniform and comprehensive basis out of a state fund. The fact that victims are taken care of as an integral part of a more comprehensive scheme is no excuse for not charging against the motor vehicle user the social costs incident to his activity. As with tires, the fact that the burden of such a gasoline surcharge would vary with speed is an advantage.

The main advantage of using gasoline rather than tires as a base is that the premium rate can be varied to a considerable extent to reflect geographical variations in risk. This does mean that to some extent at least the tax will have to be assessed on the basis of the retail outlet, but it should not be difficult to collect the tax from wholesalers on the basis of delivery records. It may also mean that drivers who drive repeatedly between low rate and high rate areas will be able to avoid the higher premiums appropriate to their driving in the high rate areas by buying preferentially in the low rate areas. But since in many cases distribution costs are higher where the premium rates would be low, a considerable variation in the premium can exist without running into more serious problems on this score. ${ }^{10} \mathrm{~A}$

${ }^{8}$ The Automobile Accident Insurance Act, I963, I2 Eliz. 2, ch. 38 (Saskatchewan), as amended, 13 Eliz. 2, ch. 5 I (Saskatchewan, 1964). For a discussion of the plan, see R. KeEton \& J. O'Conneld, Basic Protection for the Traffic Victim 140-48 (I965).

- See Derham \& da Costa, Absolute Liability, I N.Z.U.L. REr. 37 (1963); Barry, Compensation Without Litigation, 37 Austz. L.J. 339 (1964); THE Econoxist, July 13, I968, p. xxi.

${ }^{10}$ Prices can vary considerably even within the same community without driving the high price outlets out of business: regular grade gasoline retail prices vary in Palo Alto from $28.9 \%$ to $34.9 \$$ and run as high as $42.9 \$$ in other parts of California (e.g., Bridgeport). An insurance premium ranging from say 154 per gallon in San Francisco (which has the highest insurance rates of any area in the state) to say 3\% per gallon along the Nevada border should not cause any grent amount of "premium-dodging." A more serious problem would exist if a boundary between a state having such a gasoline surcharge scheme and one that does not runs through a metropolitan area; a ros or $15 \%$ differential in the gasoline tas and surcharge between Maryland and the District of Columbia, for example, would have quite serious effects on the pattern of fuel distribution. A study team of the International Bank for Reconstruction and Development has actually proposed that gasoline tax rates be higher in and near the urban centers of the Central American countries and lower in the rural areas, at least to the point where the total price would be as high in the urban center as in the remoter areas; this is however thought of 
more serious difficulty may be the problem of reconciling such differentials with uniformity clauses in state constitutions, to say nothing of the political problems involved in defending whatever rate pattern results from the application of reasonably objective economic criteria from the pressures of affected local interests.

If the notion of "insured gasoline" is to be applied in conjunction with the payment of benefits through private insurers, there is somewhat more of a problem than with tires of identifying the company to be responsible for compensating the victims of any particular accident. The most directly comparable procedure would be to use some type of tracer compound mixed in with the gasoline that would be identified by chemical analysis after the accident, but this is at best fairly clumsy and in some cases would not work at all, as when the vehicle is destroyed by fire. While some arrangement might be made for treating such cases as assigned risks, the complications this would entail detract considerably from the attractiveness of the notion as a whole. If some kind of mandatory uniform rate could be established in conjunction with a compulsory insurance scheme, it would be possible for each motorist upon signing up with a particular company to have affixed to his license plate a suitable tab, the gasoline retailer then being required to record the amount of gasoline sold to automobiles bearing the tabs of different insurers so that the appropriate amount of the premium collected with the sale of the gasoline can be credited to the proper insurer. To the extent that gasoline is sold through credit cards, an appropriate indication on the credit card would enable this to be done automatically.

Still another possibility might be for a state fund to be generated by whatever combination of gasoline tax, tire tax, and license fee surcharges is deemed appropriate, and. allow insurance companies to take on the task of settling claims relative to suitably packaged sets of automobiles on the basis of competitive bids paid out of the general fund. In principle, drivers' licenses could also be surcharged in relation to the age and other characteristics of the driver, to accomplish somewhat the same distribution of the burden as is now accomplished by the classification of the insurance companies; but while the incidence and effects of such a surcharge would be much the same as the present premium differentials, the differentials might be much more difficult to maintain as political decisions than when developed as a result of competition among private firms.

Even in the absence of mandatory legislation, the widespread use of oil-company credit cards opens up a possibility for billing for insurance coverage along with gasoline, with the insurance premium varying according to the amount of gasoline bought. This would require some means of checking on purchases of gasoline other than via the credit card: affixing a seal to the gasoline tank of the car after each credit-card purchase, together with a record of the odometer reading on the sales

as a means of reflecting congestion cost rather than accident costs. Churchill, $A$ Study of Road User Charges in Central America (Int'l Bank for Reconst. and Dev. 1968) (mimeo.) 
ticket, would afford a reasonably adequate check, permitting appropriate assessments to be made in the event of occasional purchases without the credit card. Or the premium assessed could be based primarily on the odometer readings, the tie-in with gasoline purchases serving primarily as a check that the odometer is not tampered with, it being not ordinarily worthwhile to set the odometer back by sufficiently small amounts to present a reasonable pattern.

A variety of possibilities thus exist for bringing the cost assessed against the motorist on the general activity level closer to the accident experience associated with the gross character and extent of the activity than is achieved by existing premium tariffs. Still further possibilities would be opened up if the schemes for levying congestion tolls that are being considered in England and elsewhere are implemented. ${ }^{11}$ These congestion charges are generally discussed primarily in terms of bringing home to users of congested facilities the costs they inflict on others through increasing congestion and delays, but there is nothing at all difficult about extending the concept to cover whatever additional accident risks exist in congested areas over and above those existing in noncongested areas. Indeed there is a fairly close analogy between externalities involved in accidents and those involved in congestion, the main difference lying in the existence of a fault element in many but not all of the accident situations. A gasoline-related premium could then be charged at a level representing the level of hazard in uncongested areas, with relatively little variation needed from one area to another, while the excess of the appropriate rate in the congested area over that prevailing in adjacent noncongested areas would be assessed through the congestion charge mechanism.

\section{III}

\section{Motivating Bettrir Specific Performaince}

\section{A. Post-Accident Premium Increases}

There remains the problem of what, if anything, should be done to attempt to motivate improved specific performance levels. Here the proponents of nonfault, or "workmen's compensation" treatment, go all the way to one extreme and insist that fault should have nothing to do with the payment of compensation, and that the function of penalizing the culpable parties, to the extent that the penalty inflicted by the accident itself in terms of inconvenience, uncompensated losses, and humiliation is insufficient, should take the form of fines or other penalties for identifiable misdemeanors associated with "fault." At the other extreme the pure logic of the position taken by some of the advocates of the retention of fault would seem to require that the negligent driver should be deterred by the prospect of bearing the full consequence of his negligence and that tort liability insurance, far from being compulsory, should be forbidden. It is only a very partial rescue of this

\footnotetext{
${ }^{12}$ See Walters, The Economics of Road User Charges (Int'l Bank for Reconst. and Dev. 1968) (mimeo.); Churchill, supra note 8.
} 
position to claim that classification of risks under tort insurance will retain at least some of this sanction. While to some extent the threat of being placed in a higher rate classification as a result of a claim (not necessarily one involving the fault of the insured) acts as an incentive to exercise care, the bulk of the individuals who are placed in a higher rate classification are so placed largely by circumstances beyond their control. The nineteen-year-old, male, unmarried car owner can drive with the skill of a Rickenbacker and the caution of Aunt Matilda without this having any effect on his high rate classification. In a sense, it is precisely the class of driver that most needs the incentive for which the system provides the least incentive, in that his rate is already so high it can hardly go much higher.

- Moreover the application of a significant sanction of increased rates for drivers with poor driving records is precisely one of the situations that has led to discontent with the present system. It is conceivable that with more stringent regulation of the classification process a sanction of this sort could be applied in a way that is acceptable to the public and reasonably related to the deterrent function sought for by the defenders of the fault criterion. But this would require a fairly substantial reformation of present rating practices, which look rather to the competition for the better risks, often by methods which could properly be characterized as "guilt by classification," and ignore almost completely the incentive effects of the rating scheme.

Even at best, the threat of higher insurance rates is a somewhat more remote penalty and accordingly is less effective as a sanction than a corresponding lumpsum payment at the time of an accident, though it may be possible to contemplate a larger aggregate penalty if it is spread over a number of years and can be avoided by giving up driving than if it is concentrated in a lump sum. Nevertheless, if what is wanted is a deterrent effect that does not result in incapacitating the faulty drivers financially, it does seem that something other than a retrospective rating for future premiums can be devised.

\section{B. Shared Liability as an Incentive for Care}

Indeed, if one goes as far as possible in the direction of the sanction-against-fault approach compatible with a reasonable degree of protection against catastrophe, what would seem to be called for would be some form of co-insurance or deductible amount in liability insurance. It is somewhat anomalous that liability insurance never provides for a deductible amount, so that the insured motorist is typically relieved of all burden of compensating other victims of his faulty behavior but often must bear the burden of a deductible if he is the innocent victim of an accident that is not demonstrably the fault of another, so that he must look to his own collision insurance for compensation.

Ideally, the amount of the loss to be borne by the driver at fault should be fixed in relation to his income or wealth so as to represent a sacrifice commensurate 
with the degree of fault involved. At this point one can well call for the explicit adoption of a rule of relative or comparative negligence, difficult as this may be to apply; otherwise there would be no incentive provided to comply with the admonition to "drive defensively."

\section{IV}

\section{FURTHER IMTPERFECTIONS IN THE SYSTEM}

\section{A. Liability Limits}

An even greater anomaly in the liability insurance system is the existence of liability limits. The basic purpose of insurance is to protect the insured against catastrophic events which would otherwise spell financial disaster, rather than to save him harmless from the minor adverse eventualities, particularly when these are in some measure consequences of his activities. There is no warrant either in prudence or in equity in permitting insurers to sell partial protection that leaves the way open for the bankruptcy of the insured and the inadequate satisfaction of legitimate claims. Even though the insured might rationally prefer a lower limit on the ground that, in the event of a really large claim, bankruptcy would limit the amount he would actually have to pay to much less than the full amount of the judgment, and that the extra premium he would have to pay is too much of a sacrifice when weighed against the very small chance of this serious but limited disaster to his personal fortune, it is not in the social interest to allow him this option in that his choice is in this case being made with inadequate consideration being given to the social costs involved in the unpaid judgment and his own bankruptcy and default to other creditors.

\section{B. Overhead: Contingent Fees}

Still another aspect of the problem is the distribution of the burden of the overhead costs involved in the transfer of funds from highway users to governments as taxes and as rents for the use of the facilities provided, and to accident victims as compensation. Certainly considerations of equity to the victims as well as accountability for the full social costs occasioned by accident-prone activity would call for all of these overhead costs, except possibly those associated with collections of outright taxes (as distinct from user charges), to be borne by the highway user rather than the accident victim. Yet the legal theory generally in effect in the United

\footnotetext{
${ }^{12}$ Comparative negligence statutes have been enacted in Mississippi, Nebraska, Wisconsin, South Dakota, and Arkansas. The Nebraska and South Dakota statutes apply only when flaintiff's negligence is "slight" compared with that of defendant. Georgia has adopted comparative negligence by giving general application to a statute designed only for railroad accidents. W. Prosser, HANDBOoK on THE Lsw of Torts 443-49 (3d ed. I964). The Illinois Appellate Court recently adopted comparative negligence after being directed to consider the issue by the Illinois Supreme Court. Maki v. Frelk, 85 IIl. App. 2d 439, 229 N.E.2d 284 (1967). See Comment, Judicial Adoption of a Comparative Negligence Rule in Illinois, 1967 U. ILI. L.F. 35 I.
} 
States denies any allowance with respect to the claimant's attorney's fees in the amount of the award, leaving the claimant to receive, net, substantially less than the sum that has been adjudged necessary to make him whole. For cases where a lawyer is retained, the lawyer's fee typically absorbs a quarter to a third of the gross settlement, leaving the victim substantially undercompensated. ${ }^{13}$ To be sure, juries in determining amounts to be awarded with respect to the intangible factors of "pain and suffering" may inflate this element somewhat to allow for the lawyer's share, but at least in those cases where the amount of the claim is fairly well defined in terms of out-of-pocket costs and actuarial evaluations, there may be little room for such extralegal justice.

The reluctance of courts to award damages inclusive of claimants' costs is to some extent related to the prevalence of the contingent-fee basis of handling claims, which, although dominant in United States accident practice, is considered unethical and even unlawful in other jurisdictions. Under such circumstances the legal fee, being defined in terms of the gross settlement, is less directly related to the time, effort, and out-of-pocket costs involved in representing the specific client. Especially where the lawyer involved has other dealings or relationships with the claimant, there might arise some suspicion that the stated legal expenses might be inflated; even when the matter is at arm's length, the notion that the lawyer's fee would be paid out of the settlement or not at all may generate too much of a temptation for the claimant to insist on prolonging litigation.

\section{Obstacles to Fair Settlements}

It should be noted that this tendency of the courts to exclude claimants' attorneys' fees in awarding damages has a significant influence on cases settled out of court and even cases settled prior to the retention of a lawyer, in that such exclusion permits insurers to hold out for a settlement in terms of the actual provable loss less a hypothetical attorney's fee, since that is the maximum the claimant could obtain by going to court. The relative bargaining power of the parties is such that an attempt on the part of the claimant to obtain better terms by threatening to retain a lawyer or take the case to court is unlikely to succeed in obtaining significantly better treatment unless, indeed, the insurer is induced by public relations considerations or the like to refrain from pressing its advantage.

Still another sinister element in the bargaining over claim settlement is the impact of the liability limit. Insurance companies often insist on carrying a case to court in the face of an offer of settlement satisfactory to the insured, motivated by the likelihood that if the court award turns out to be lower than the offer of settlement the insurance company will be the gainer, but in the case of a substantially higher award that exceeds the policy limits the insured will be liable for the excess. In flagrant cases of this kind courts have recently held the insurer

\footnotetext{
${ }^{23}$ See Franklin, Chanin \& Mark, supra note 5, at 20-30.
} 
liable for the full award regardless of the policy limit, ${ }^{14}$ but to achieve this result not only does there have to be a separate suit by the insured against the insurer, but the offer or possibility of out-of-court settlement has to be sufficiently patent to be provable in court. Thus while these recent decisions have helped somewhat in the more flagrant situations of this kind, the tendency of insurers to take an undue number of cases to trial against the interests of their policyholders remains a serious one. The prevalence of this tendency is still another cogent reason for the abolition of policy limits.

\section{Reform of the Settlement Process}

It should be possible to develop rules of procedure in settling claims that will be much more conducive to rapid settlement, out of court, with lower costs of settlement and greater equity than characterize the present procedures. In developing such procedures it is important to get rid of the fiction that the case is between two individuals of equal resources and bargaining power, and recognize explicitly that the typical case is between an individual of limited means and a large insurance company. Formal symmetry in such a situation is not only not required, it is out of place.

A basic step in developing such a procedure would be to provide that once the basic amount of a lump-sum award has been determined by the court, then unless a record can be produced of a bona-fide offer of settlement for a figure at least as great as the amount of this award plus the claimant's reasonable costs incurred in good faith up to the date of the offer, the entire costs of the claimant will be added to the basic award. If such a record is produced, the award will be increased by the amount of the claimant's costs incurred up to the date of the first offer meeting this condition. Any such offers of settlement would, of course, not be admissible evidence prior to the determination of the basic award. One could appropriately include in the costs for this purpose interest at a rate at least equal to that typically charged for low-grade consumer credit, say ten to fifteen per cent per year. It should not be too difficult to develop analogous provisions for dealing with cases where the settlement is not in terms of a lump sum.

While one could provide, symmetrically, that where a record is produced of an offer that is adjudged adequate according to the above criterion and which was refused by the claimant, the award to the claimant would be diminished by the insurer's costs of handling the case subsequent to the qualifying offer, this nominally even-handed treatment seems not to be called for in view of the resources of the

\footnotetext{
${ }^{14}$ See, e.g., Crisi v. Security Ins. Co., 66 Cal. $2 \mathrm{~d} 425,426$ P.2d 173, 58 Cal. Rptr. 13 (1967); State Farm Mutual Auto. Ins. Co. v. White, $248 \mathrm{Md}$. 324, $236 \mathrm{A.2d} 269$ (1967). Dicta in the Crisi case indicate that the California courts may be headed toward strict liability for failure to accept settlement within the insured's policy limits. See Comment, Crisi's Dicta of Strict Liability for Insurer's Failure to Settle: $A$ Move Toward Rational Settlement Behavior, 43 Wast. L. Rev. 799 (1968). See generally Annot., 40 A.L.R.2d I68 (1955).
} 
parties. Indeed, there might be some difficulty in separating out the costs of the insurer applicable to a particular case; moreover in the event of a claimant's being held not entitled to any award, the result would nominally require a net payment by the claimant to the insurer, which could result in an undesirable degree of hardship. Realism is more important here than formal symmetry.

\section{Some Reflections on Compensable Damages}

\section{A. Pain and Suffering}

Another element in the evaluation of the amount to be paid the victim that is difficult to determine and the subject of much controversy is that of compensation for "pain and suffering." Being essentially subjective in nature, it is difficult to evaluate, particularly in the individual case; moreover, the lengths to which attorneys and the litigants they represent are often induced to go in attempting to play upon the sympathies of juries in an effort to obtain a higher award with respect to this element are often not such as to reflect credit on the judicial process. The difficulties of determining the proper amount to be awarded on this basis have indeed led many proponents of reform in auto accident compensation to advocate elimination of this factor in whole or in part. To eliminate this element in damages, however, would to that extent depart from the ideal of justice to suffering victims. It does seem possible, though perhaps not as easy as it might seem at first, to arrive at some form of more or less arbitrary compromise formula that will eliminate the need for the unseemly histrionics while at the same time coming closer to justice than limiting recoveries to bare out-of-pocket costs. One simple rule might be to allow under this heading an amount equal to some percentage of all associated medical expense. The main difficulty is that this would furnish the victim with an incentive to pad such medical bills. A schedule of fixed amounts with respect to varying categories of injury would be somewhat arbitrary, but certainly better than no allowance at all and probably better than the capricious results of present practice.

But whatever doubts one might have as to the advisability in practice of paying ill-defined amounts to the victims with respect to pain and suffering, there can be no doubt that some global allowance for the pain and suffering caused by automobile accidents in general should be an element of the charges levied against those engaging in the activities responsible for this pain and suffering. To argue otherwise is, in effect, to assert that in deciding between alternative means of attaining an objective no consideration should be given to the relative amounts of pain and suffering involved in their use. Just as it is proper and efficiency-promoting to charge the individual motorist who contributes to congestion even though it would be impractical and to a degree self-defeating to attempt to distribute the amounts collected among the specific motorists who are adversely affected, it is proper to charge motorists an amount reflecting the over-all aggregate of pain and suffering 
resulting from their activity, even though there may be insuperable obstacles to distributing the amounts so collected equitably among the specific victims.

\section{B. Allowance for Alternative Sources of Compensation}

An even clearer case occurs when consideration is given to what, if any, account should be taken of other sources of accident compensation available to the victim, such as Blue Cross, sick-leave provisions in labor contracts, social security, income-tax deductions and exemptions, and the like. It is indeed inequitable that some individuals, as happens not infrequently, should obtain in effect duplicate compensation for their damages so as to emerge actually better off as a result of the accident. ${ }^{15}$ Many reform plans, indeed, including the Keeton-O'Connell proposal, have proposed that awards made to victims be reduced to allow in full for all of these other sources of compensation available to the victim, including even the fact that the award itself is not subject to income tax. ${ }^{16}$ From the standpoint of what is required to make the victim whole, this position is indeed sound in principle, though one would have to be careful in applying it so as not to unduly discount such elements as the fact that use of sick leave on account of an automobile accident might diminish the amount of such allowances available in case of a subsequent illness or disability.

What is true of the amount to be paid to the victim, however, is again not true of the appropriate amount to be charged to the automobile user. The activity causing the accident has inflicted losses on the employer who pays the sick-leave benefits, or on Blue Cross subscribers generally whose rates will have to be increased, in the long run, if the added cost of caring for such accident victims is to be covered. Thus while it may be appropriate to reduce compensation awards on one or more of these grounds, it is definitely not appropriate to reduce the premiums or other charges assessed against motorists on this ground. Rather, if it proves impossible to arrange payments from insurance funds to compensate the adversely affected employers, Blue Cross plans, and the like, it still becomes appropriate to have a corresponding sum collected from motorists and paid to some appropriate government agency, merely as a means of keeping the cost to the motorist of his use of highways in line with the true social costs and thus inhibiting excessive development of this accident-prone activity.

Accordingly the attempt of the developers of the Basic Protection Plan to seize on these sources of compensation as a means of reducing the premiums required to be paid by motorists is wrong in economic principle, however much it may contribute to the political attractiveness of their proposal in the land of the rubber-shod sacred

\footnotetext{
${ }^{15}$ See James, Social Insurance and Tort Liability: The Problem of Alternative Remedies, 27 N.Y.U.L. Rev. 537 (1952). Insurance is generally not to be considered in computing damages, C. McCormrck, HandBoor on the Law of Danages $310 \mathrm{n.2}, 323,324 \mathrm{n} .12$ (r935), and the fact that a defendant docs or does not have insurance is not usually admissible in evidence. C. McCormick, HandBook on THE LAW OF Evidence 355-58 (I954).

10 R. KeEton \& J. O'ConNell, supra note 6 , at $278-80$.
} 
cow. Actually much of the savings might turn out to be relatively short-lived, for if Blue Cross, sick leave, and other benefits once become generally deductible in computing accident compensation awards, it is not likely to be long before Blue Cross insurance plans, employers, and others making such payments insert clauses in their contracts denying payment where accident compensation is available, if indeed such clauses are not already fairly prevalent.

\section{VI}

\section{Modifying the Systent}

\section{A. Inefficiency of the Transfer Process}

Before all of the above economic analysis is taken up at face value, however, some recognition is required of the extreme costliness and inefficiency of the entire process by which funds are transferred from the automobile user to the victim. Indeed, this inefficiency is so extreme that, unless some means can be found to improve the situation, what might under less costly operating conditions be decmed roughly adequate arrangements become highly questionable simply because the leakage is so high. If, for example, of every $\$ 100$ paid in by the motorist the victim were to receive, say, $\$ 99$, then one might be willing to insist that the system of compensation should come reasonably close to making the victim whole. If, however, as seems to be the current situation in the United States, it costs the motorist well over $\$ 200$ to put $\$ 100$ into the pockets of the victim, one may well want to stop short of doing exact abstract justice to the victim at a cost of this magnitude.

This cost is clearly chargeable primarily to the function of putting the money in the pockets of the victim and only slightly to that of charging appropriate social costs to motorists. While in a sense the cost of premium collection can be thought of as a cost of charging social costs to motorists, it is clear that the premium collection system is neither designed with this end in view nor particularly well adapted to its accomplishment. This end can be achicved accurately enough for most purposes at negligible overhead costs simply by raising the level of gasoline and other vehicular taxes.

The cost of operating the automobile accident compensation system can be set forth as follows: Total automobile insurance premiums earned in 1967 amounted to $\$ 8.9$ billion, to which would have to be added some 0.4 billion of interest earned on these funds between the time of receipt of the premiums and the time of payment of the claims; losses incurred amounted to $\$ 5.4$ billion. Not all of this latter amount reached claimants, however; Conard's Michigan study showed that claimants in accident cases involving bodily injury spent $\$ 11.8$ million to obtain a total of $\$ 64.3$ million in tort settlements and payments on their own automobile insurance policies, or over eighteen per cent. ${ }^{17}$ If the same ratio applied generally, this would mean on a national scale about $\$$ r.o billion of collection expenses, leaving

\footnotetext{
${ }^{17}$ A. Conard et al., satpra note 4 , at $\approx 38-39$.
} 
a net payment to victims of $\$ 4.4$ billion out of the total of $\$ 9.3$. The above figures, moreover, include payments to policyholders under collision, medical payments, and other similar insurance; if attention were focused on tort liability payments the picture would be even worse.

\section{B. Reducing Overhead Costs}

This $\$ 4.9$ billion of unproductive overhead in the accident compensation process can be split between $\$ 2.5$ billion for the collection of premiums, and $\$ 2.4$ billion for the payment of benefits. ${ }^{18}$ Anything that can reduce these costs is of direct benefit. On the other hand, while reductions in the aggregate amount of benefits paid do not in themselves constitute a reduction in costs, and indeed are likely to redistribute the costs more inequitably and to increase inefficiency, a reduction in the aggregate amount of benefits would at least be likely to induce a reduction in the waste of resources in unproductive overhead costs. The relationship is by no means a firm one, however, and some reductions in benefit payments might well have only a small or even an adverse effect on these overheads. In particular, the proposal to require compensation to be computed net of alternative sources of compensation might require additional investigative expenditures to ascertain their availability and amount.

The costs of paying benefits, in turn, can be conceptually split between the cost of ascertaining fault and the cost of ascertaining damage. While much of the criticism of the existing system has focused on the high cost and low reliability of the fault ascertainment process, little hard evidence seems to be available as to the relative costs involved. If one postulates as a rather daring guess that these costs are split half and half, this would in effect mean that the question of retention of the fault system is essentially one of balancing a cost of $\$ \mathrm{r} 2$ billion plus whatever contribution the system makes to the demoralization of the judicial process against the benefits of whatever deterrent to reckless behavior filters through the insurance system (via the rating of risks on the basis of past individual experience) plus the avoidance of whatever repugnance there may be to the payment of benefits to victims of their own negligence. At this point the accident bar may in effect bellow "Fiat justitia, ruat coelum," but economists are likely to inquire whether more significant increments of justice are not to be had in other areas at far less cost. Costly justice is inferior justice, if indeed it is not actually injustice in disguise.

If reduction in the cost of handling compensation for automobile accidents is a main objective, it seems clear that the collection of premiums as an integral part of gasoline and other highway user taxes would be the most important single measure, bringing about a substantial savings per year at current levels. Elimination of fault as a barrier to recovery and as a determinant of the source of payment

\footnotetext{
${ }^{19}$ Best's Fire and Casualty Aggregates and Averages (I967).
} 
would be another substantial element in such cost reduction. The most intractable element in the overhead costs is that of ascertaining the amount of the allowable claim. Elimination of the intangible elements of "pain and suffering" would be an important factor here; alternatively, the use of some form of arbitrary formula might also eliminate much of these costs, though raising problems in other directions through creating incentives for the padding of costs. It is to be noted, however, that because of the way in which these various administrative costs interact, once premium payment costs and fault ascertainment costs have been substantially eliminated, the importance of reducing the costs of ascertaining the amount of claims will be reduced, since these costs are then no longer magnified by these other overheads.

Such considerations obviously point fairly strongly in the direction of handling automobile accident compensation through a public or semipublic agency, with benefit payments financed out of increments to or variations on the existing system of motor vehicle user charges and paid largely without regard to fault.

\section{Reform of the Private Insurance System}

If, on the other hand, some form of private insurance based on fault is to be retained because of a desire to provide appropriate sanctions for careful driving, reinforced by a deeply ingrained preference for private rather than public enterprise, the system needs to be drastically revised in a number of ways.

First, some form of comparative negligence doctrine needs to be explicitly endorsed in order to preserve an incentive for "defensive" driving beyond the point of mere avoidance of what is now legally recognized as "fault." This does not mean that if both drivers involved in a two-car accident are held to be equally at fault neither of them should have a claim against the other, and each should be left to nurse his own wounds, as is presently the result under the doctrine of contributory negligence where only liability insurance is carried; rather, in such a case the two parties should be held, through their insurers, to share equally in liability for the combined damage; nor should the liabilities be netted out so as to leave no claim against the insurer of the car suffering the greater damage.

In theory, if drivers $\mathrm{A}, \mathrm{B}$, and $\mathrm{C}$ are involved in a collision, incurring damage in the amounts of $X, Y$, and $Z$ respectively, and if the relative responsibility for the accident is fixed at $p$, $q$, and $r$, with $p+q+r=1$, then $A$ together with his liability insurer would be called on to pay $\mathrm{pY}$ to $\mathrm{B}$ and $\mathrm{pZ}$ to $\mathrm{C}, \mathrm{B}$ together with his liability insurer would pay $\mathrm{qX}$ to $A$ and $\mathrm{qZ}$ to $\mathrm{C}$, and $\mathrm{C}$ together with his liability insurer would pay $r X$ to $A$ and $r Y$ to $B$. The balance of the loss would be covered, if at all, by collision, medical payments, or other nonliability insurance, the amounts collected by each from his own insurer, in the event such insurance coverage is in force, being $\mathrm{pX}, \mathrm{qY}$, and $\mathrm{r} Z$, respectively. 
Second, if any rationale at all is to be retained for the fault procedure, parties at fault must be required to provide some substantial but not crippling contribution to the payment of claims, and the covering of this contribution by insurance policies must be forbidden. The deductible amount might be specified by some such formula as all of the first \$roo of the liability resulting from any one accident, plus one-third of the liability, up to a maximum in any one twelve-month period of a sum to be specified in the policy and required to lie between, say, ten and thirty per cent of the insured's average federal income tax liability over the preceding three years. Specification of too low a deductible would incur the penalty that in the event of an accident the minimum limit would nevertheless be used as the deductible amount. Specification of a deductible in excess of the lawful maximum would carry the penalty that if the insurance company permits such a minimum to be written into the policy, and the insured proves unable to meet a judgment, the insurer will nevertheless be liable for all judgments above the maximum permissible deductible. To avert hardship to victims where the responsible party is unable to pay the deductible portion of the award specified in conformity to stipulations such as the above, an unsatisfied judgment fund would have to be set up to provide for such payments to be made promptly on behalf of those adjudged partly or wholly at fault, with the right of such parties to own or operate automobiles being either denied completely or being conditioned on suitable surcharges or installments being paid until the fund has been reimbursed.

Even with these refinements, it seems possible that it will be considered that the application of the fault criterion fails to result in sanctions that will have a worthwhile effect on the care with which people drive, and that a decision will be made to abandon the fault criterion either in whole or in part. But whether or not the fault criterion is used, retention of private insurance in any form as the major element in accident compensation would seem to require the following additional measures.

Third, while it has been said that every dog is allowed one bite, the financial responsibility laws which allow every driver one accident carry too much risk of throwing on society the costs associated with unrecovered losses of the victims or the bankruptcy and disability of the driver at fault. Even if fault is eliminated, there is no warrant for allowing automobile users to throw their losses onto the community through bankruptcy or reliance on free or subsidized community services. There seems to be no satisfactory alternative short of universal compulsory insurance, whether under private or public auspices or some combination of the two.

Fourth, for somewhat comparable reasons, insurance must be without upper bound on the amount of a judgment or loss for which the insurer will stand liable. This system has caused no great difficulty in countries where it exists, and while the contention is made that in the absence of specific limits juries would tend to make 
excessive awards, data available do not indicate that this is a serious danger: ${ }^{10}$ the more serious danger is that of leaving victims with grossly inadequate compensation and defendants in bankruptcy. Moreover, in a fault system the existence of policy limits introduces a serious conflict of interest between the insurer and the insured in the settlement process, leading not only to inequitable results but to increased delays and litigation.

Fifth, claimants should be entitled to recover, in addition to their damages, any reasonable costs of prosecuting their claim up to the time when an offer of settlement is made on terms determined to be adequate. This is important not only as a matter of justice but as a means of reducing delays in settlement and the number of cases brought to trial.

Sixth, while consideration may well be given to reducing the amount of compensation collectible by the victim in the light of other forms of compensation available, such reduction should not operate to reduce the premiums payable by motorists: rather, any reductions made on this account should be offset by payments either into a state general fund or payments to the payors of the other forms of compensation as associated injured parties. The practical difficulties of discovering on a reasonably uniform basis all of the various forms of such alternative compensation may, however, be such as to make this on balance not worthwhile. In any case, unless the general level of compensation, especially for the larger claims, can be substantially increased, the number of cases of overcompensation arising from this source is not likely to be a serious inequity.

Seventh, premiums should eventually be made to vary, by one means or another, much more nearly in proportion to the actual mileage travelled. In the meantime, data should be collected that will provide information as to how the cost of accidents varies with the number of miles per year a vehicle is driven.

Finally, it should be noted that even if the concept of fault, in the sense of improper behavior at the time of the accident, is eliminated entirely in the settlement of accident compensation cases, this does not mean that one can automatically abandon third-party liability or even that one can properly restrict such liability to a small number of cases. If, as is sometimes suggested, the insurer of each car should undertake to compensate, subject to the appropriate deductibles, for all damage to that car and injury to its occupants regardless of fault, there still remains the apportionment of liability for damage to wayside property and injuries to pedestrians (eighteen per cent of all motor vehicle deaths are pedestrians). Also, from another standpoint, types of vehicles differ widely in their propensity to inflict damage on other vehicles and their occupants relative to their own susceptibility to such damage. If an ancient Cadillac encounters a brand new Volkswagen, the

\footnotetext{
${ }^{19}$ See Kalven, The Jury, the Law, and the Personal Injury Damage Award, 19 Ono ST. L.J. 158, I7x (1958). While jurors may suppose that a defendant is insured, they are never told this fact, nor are they informed of the limits of defendant's coverage. See note $\mathrm{r}_{3}$ supra.
} 
damages sustained are not likely to be the same on both sides, either to the cars or the occupants. If each car is insured to cover damages to itself and its occupants, the premiums are unlikely to bear any very close proportionality to the expected amount of accidental damage that the operation of that vehicle will cause. Even more important is the relation between premiums charged trucks and those of other vehicles: trucks are especially likely to inflict more damage on other vehicles than they sustain themselves. Attractive as the notion is of having victims deal only with their own insurers, it cannot be applied at all to injuries to pedestrians and roadside property and cannot be applied as among motor vehicles without serious misallocation of costs on the over-all activity level, including a substantial subsidy to trucking from other motor vehicle usage.

\section{SUMMARY}

The pattern of reform that emerges from looking at the problem of motor-vehicle accident compensation through the economist's spectacles differs considerably from that produced from the lawyer's or politician's viewpoint. Reduction in cost is desired, but only if it is a genuine reduction in the wasteful overheads, not if it is a mere reduction in the size of the transfers to the injured on one pretext or another. The payment of insurance premiums is seen as intimately related to other types of highway user charges, even without the added possibility of substantially lowering overhead costs through integration or coordination of these charges with one another. Given the strongly entrenched vested interests of automobile users, the automotive industry, the accident bar, the insurance industry, and their agents, it is too much to hope that the above suggestions will be implemented on any wide scale in the immediate future. But they do deserve careful examination, if only as a contribution to a logical and rational approach to the problem. 